\title{
Enhanced Antioxidant Effect of Black Soybean by Cheonggukjang with Potential Probiotic Bacillus subtilis CSY191
}

\author{
Chung Eun Hwang, Weon Taek Seo, and Kye Man Cho* \\ Department of Food Science, Gyeongnam National University of Science and Technology, \\ Jinju 660-758, Republic of Korea
}

\section{잠재적인 생균제제 Bacillus subtilis CSY191에 의한 검정공 청국장의 항산화 증진 효과}

\author{
황정은 · 서원택 · 조계만* \\ 경남과학기술대학교 식품과학부
}

(Received September 30, 2013 / Accepted November 6, 2013)

\begin{abstract}
Changes in $\beta$-glycosidase activity, total phenolic and isoflavone contents, and antioxidant activities during the fementation of Korean black soybeans (Seoritae and Seomoktae) fermented food cheonggukjang by the potential probiotic Bacillus subtilis CSY191 were investigated. The levels of total phenolic and isoflavone-malonylglycoside and -aglycone contents increased, while 2,2-azinobis (3-ethyl-benzothiazoline-6-sulfonic acid) diammonium salt (ABTS) radical scavenging activity and feric reducing/antioxidant power (FRAP) increased, but the isoflavone-glycoside contents decreased after cheonggukjang fermentation. The content of antioxidant compounds, including isoflavone-aglycones and -malonylglycosides, was increased by fermenting-processing, whereas the content of isoflavone-glycosides was decreased in the fermented soybeans. In particular, the Seoritae soybean fermented at 3 $7^{\circ} \mathrm{C}$ for $48 \mathrm{~h}$ displayed the highest antioxidant activities, compared to those of the Seomoktae soybean and the fermented. The highest levels of daidzein, glycitein, and genistein were present at concentrations of $253.0 \mu \mathrm{g} / \mathrm{g}, 72.5$ $\mu \mathrm{g} / \mathrm{g}$, and $114.1 \mu \mathrm{g} / \mathrm{g}$ after $48 \mathrm{~h}$ of Seoritae soybean fermentation. From those results, we suggest that the high antioxidant activity of cheonggukjang of black soybeans might be related to the markedly higher levels of total phenolic and isoflavone-aglycone and -malonylglycoside contents achieved during fermentation.
\end{abstract}

Keywords: Bacillus subtilis CSY191, antioxidant activity, black soybean, cheonggukjang, isoflavones

Black soybeans (Glycine max L. Merrill) have been widely consumed as folk medicines in China, India, Japan, and Korea for hundreds of years (Jeong et al., 2010) and have various biological effect such as osteoblastic cell proliferating, anticancer, and antioxidant activity (Kim et al., 2011). Black soybeans are increasingly sought after in food and medicinal industries because of their various beneficial effects (Lee and Cho, 2012). Previously, numerous researchers have reported that the beneficial properties of black soybeans are due to the many phytochemicals present in the crop, including isoflavone, flavanol, flavan-3-ol, anthocyanin, and saponin (Lee and Cho, 2012). In Korea, black soybeans are used to prepare several different traditional fermented foods, including тејu (soybean

*For correspondence. E-mail: kmcho@gntech.ac.kr; Tel.: +82-55-7513272; Fax: +82-55-751-3279 cake), cheonggukjang (soybean cook), kanjang (soybean sauce), and doenjang (soybean paste). In particular, cheonggukjang is manufactured in a traditional way in homes using different types of processes, depending on the region; thus its physicochemical and functional properties vary due to differences in soybeans, microorganisms, and fermentation time (Nam et al., 2012).

In raw soybeans, isoflavones are present in four chemical forms: malonylglycosides (70-80\%), acetylglycosides (5\%), glycosides (25\%), and aglycones (2\%) (Lee and Choung, 2011). Isoflavones conjugated glycoside are converted to aglycones under acidic or alkaline conditions or by the action of $\beta$ -glycosidase. The aglycone forms show greater potential for absorption in the intestine than the glycoside forms (da Silva et al., 2011, FC). Incorporation of $\beta$-glycosidase has attempted to increase the content of isoflavone-aglycones in cheonggukjang (Yang et al., 2006; Cho et al., 2009, 2011). In addition, several 
researchers have reported that total phenolic and isoflavoneaglycone contents increased, depending on whether antioxidant activities increased after cheonggukjang fermentation (Cho et al., 2009, 2011; Hu et al., 2010).

The objective of this study was to compare the antioxidant activities observed in cheonggukjang fermentation of two Korean black soybeans, such as Seoritae and Seomoktae. In addition, we investigated the possibility that the enhancing effect of fermentation on the antioxidant activities observed during cheonggukjang of Korean black soybeans that may be related to the total phenolic contents and isoflavone compositions of this product.

\section{Materials and Methods}

\section{Black soybeans, microorganism, chemicals, and instruments}

Two black soybean samples (Seoritae and Seomoktae) were harvested in 2011 and were purchased from the local market in Jinju, Korea. The potential probiotic Bacillus subtilis CSY191 previously isolated from Korean traditional soybean paste (doenjang), was used as the starter organism (Lee et al., 2012).

Three isoflavone aglycones, including daidzein, genistein, and glycitein, were obtained from Sigma-Aldrich Chemical Co. (USA), and three isoflavone glycosides, including genistin, daidzin, and glycitin, were purchased from Indofine (Hillsborough, USA). Three malonyl- and three acetyl-isoflavone glycosides (malonylgensitin, malonylglycitin, malonyldaidzin, acetylgenistin, acetylglycitin, and acetyldaidzin) were purchased from LC Laboratories (Woburn, USA). HPLC-grade $\mathrm{H}_{2} \mathrm{O}$, methanol, and acetonitrile were purchased from Fisher Scientific (Fairlawn, USA). Glacial acetic acid, Folin-Ciocalteu phenol reagent, 2,2-azinobis (3-ethyl-benzothiazoline-6-sulfonic acid) diammonium salt (ABTS), potassium persulfate, ferric chloride, sodium acetate, 2,4,6-tripyridyl-s-triazine (TPTZ), and rutin were obtained from Sigma-Aldrich Chemical Co. All other reagents were of analytical grade.

The UV spectra were measured with a Spectronic 2D spectrophotometer (Thermo Electron Co., USA). HPLC was performed using an Agilent 1200 series system (Agilent Co., Australia) equipped with a quaternary HPLC pump, a degasser, and an Agilent 1200 series diode array detector (DAD). The isoflavones were analyzed on a LiChrospher 100 RP C18 column (4.6 × $150 \mathrm{~mm}, 5 \mu \mathrm{m}$; Merck, Germany).

\section{Fermentation of black soybean}

Two whole black soybeans $(1,000 \mathrm{~g})$ were washed and soaked with three volumes a tap water at $20 \pm 2^{\circ} \mathrm{C}$ for $12 \mathrm{~h}$, and steamed for $15 \mathrm{~min}$ at $121 \pm 1^{\circ} \mathrm{C}$. The steamed soybeans were left to stand for $1 \mathrm{~h}$ at $38 \pm 1^{\circ} \mathrm{C}$ to cool down. Then, the cooked black soybeans were inoculated with $5.0 \%(\mathrm{w} / \mathrm{w})$ strain CSY191 (7.65 log CFU/ml) and fermented for $24 \mathrm{~h}$ at $37 \pm 2{ }^{\circ} \mathrm{C}$ in an incubator and sampled at 0 and $48 \mathrm{~h}$.

\section{Viable cell number and $\beta$-glycosidase activity}

Ten gram of sample was mixed with $90 \mathrm{ml}$ of $0.85 \% \mathrm{NaCl}$ solution and the diluted suspension ( 0.1 portions) was spread on a TSA plate. The plates were incubated at $37^{\circ} \mathrm{C}$ for $24 \mathrm{~h}$, after which colony counts were carried out.

The method described by Cho et al. (2011) was used to determine the $\beta$-glycosidase activity. Ground cheonggukjang $(1.0 \mathrm{~g})$ was mixed with $20 \mathrm{ml}$ of $50 \mathrm{mM}$ sodium phosphate buffer ( $\mathrm{pH} 7.0$ ), vortexed for $1 \mathrm{~min}$, and centrifuged at $6000 \times \mathrm{g}$ at $4{ }^{\circ} \mathrm{C}$ for $30 \mathrm{~min}$. The supernatant was collected and filtered through a $0.45-\mu \mathrm{m}$ filter before analysis. The $\beta$-glycosidase activity in the crude extract was assayed by determining the rate of hydrolysis of $p$-NPG. The crude extract $(250 \mu \mathrm{l})$ was added to $250 \mu \mathrm{l}$ of substrate ( $5 \mathrm{mM} p$-NPG) in $50 \mathrm{mM}$ sodium phosphate buffer ( $\mathrm{pH} 7.0$ ). After $30 \mathrm{~min}$ of incubation $37^{\circ} \mathrm{C}$, the enzymatic reaction was stopped by adding $500 \mu \mathrm{l}$ of $0.2 \mathrm{M}$ glycine- $\mathrm{NaOH}(\mathrm{pH}$ 10.5) and the contents were immediately measured in a spectrophotometer at $405 \mathrm{~nm}$. The blank solution was composed of $2.5 \mathrm{ml}$ of $50 \mathrm{mM}$ glycine- $\mathrm{NaOH}, 2.0 \mathrm{ml}$ of substrate solution, and $0.5 \mathrm{ml}$ of $50 \mathrm{mM}$ citric buffer ( $\mathrm{pH} 4.5$ ) containing $0.1 \mathrm{M} \mathrm{NaCl}$. The $p$-NP released by the action of the enzyme was determined by referring to a calibration curve prepared from the $p$-NP in concentrations that varied from 5 to $300 \mathrm{mM}$. One unit of $\beta$-glycosidase activity was defined as the amount of enzyme that liberated $1 \mu \mathrm{M}$ of $p$-NPG.

\section{Isoflavone extraction and analysis}

The isoflavone extract and analysis were performed as previously described (Cho et al., 2011). Briefly, each of the ground powders $(10 \mathrm{~g})$ was extracted with $100 \mathrm{ml}$ of $50 \%$ methanol by shaking $(320 \mathrm{rpm})$ at $30^{\circ} \mathrm{C}$ for $12 \mathrm{~h}$; the extracts were filtered through Whatman No. 2 filter paper (GE Healthcare Life Sci., USA) and then filtered through a $0.45-\mu \mathrm{m}$ Millipore PVDF filter (Schleicher \& Schuell, Germany). Samples of the filtrates were used for HPLC analysis. The rest of the filtrates were dried under a vacuum. The dried samples were stored at $-70^{\circ} \mathrm{C}$ in the dark until further use in antioxidant activity assays, and then the dried materials were redissolved in $50 \%$ methanol at $1 \mathrm{mg} / \mathrm{ml}$.

The isoflavones were analyzed by HPLC. A $20 \mu$ sample of the crude $50 \%$ methanol extracts was injected onto an analytical $\mathrm{C}_{18}$ column with the column temperature set to $30^{\circ} \mathrm{C}$. The isoflavones were detected by monitoring the elution at 254 $\mathrm{nm}$ using a DAD. The isoflavones in the samples were identified by comparing their retention times to those of 
Table 1. Change of viable cell numbers and $\beta$-glycosidase activities during cheonggukjang fermentation of black soybeans by B. subtilis CSY191

\begin{tabular}{cccc}
\hline \multirow{2}{*}{$\begin{array}{c}\text { Soybean } \\
\text { Cultivars }\end{array}$} & Samples & \multicolumn{2}{c}{ Contents $^{\text {1) }}$} \\
\cline { 3 - 4 } Seoritae & UFBS $^{2}$ & Viable cell numbers $(\log$ CFU/g) & $\beta$-Glycosidase activity (Unit/g) \\
& FBS $^{3)}$ & $5.01 \pm 0.20^{\mathrm{b}}$ & $4.2 \pm 0.11^{\mathrm{b}}$ \\
\hline \multirow{2}{*}{ Seomoktae } & UFBS & $11.19 \pm 0.62^{\mathrm{a}}$ & $22.8 \pm 1.11^{\mathrm{a}}$ \\
& FBS & $4.81 \pm 0.18^{\mathrm{b}}$ & $4.0 \pm 0.22^{\mathrm{b}}$ \\
\hline
\end{tabular}

${ }^{1)}$ Values indicate the mean's of three replications $(n=3)$. All values are means of determinations in three independent experiments. Means with different lowercase letters ( $\mathrm{a}$ and $\mathrm{b}$ ) indicate significant differences of fermentation times by Tukey's multiple range test $(p<0.05)$.

${ }^{2)}$ Unfermented black soybeans

${ }^{3)}$ Fermented black soybeans at $37^{\circ} \mathrm{C}$ for $48 \mathrm{~h}$.

standards. The mobile phase was composed of $0.1 \%$ glacial acetic acid in water (solution $\mathrm{A}$ ) and $100 \%$ acetonitrile (solution $\mathrm{B}$ ). The gradient conditions were as follows: 0-20 min, $10 \% \mathrm{~B} ; 30$ $\min , 20 \% \mathrm{~B}$; $40 \mathrm{~min}, 25 \% \mathrm{~B}$; and $50 \mathrm{~min}, 35 \% \mathrm{~B}$. The solvent flow rate was maintained at $1 \mathrm{ml} / \mathrm{min}$.

\section{Total phenolic contents (TPCs)}

A method based on that of Cho et al. (2011), which uses gallic acid equivalents (GAE) was used to quantify the TPCs in the $50 \%$ methanol extracts. A $500 \mu \mathrm{l}$ aliquot of each isoflavone extracts was mixed with $250 \mu \mathrm{l}$ of $2 \mathrm{~N}$ Folin-Ciocalteu's reagents. After standing at room temperature for $3 \mathrm{~min}$, a $500 \mu \mathrm{l}$ aliquot of a $25 \%$ sodium carbonate $\left(\mathrm{Na}_{2} \mathrm{CO}_{3}\right)$ solution was added, and that mixture was allowed to stand at room temperature for $1 \mathrm{~h}$. Quantification was performed using a linear regression equation on the gallic acid standard curve. Five gallic acid standard solutions of 100, 250, 500, 750, and 1000 $\mathrm{mg} / \mathrm{L}$ were prepared in deionized water, and $500 \mu \mathrm{l}$ of each standard solution was collected and prepared using the same procedure described above, the absorbance of the solution was measured at $750 \mathrm{~nm}$, and a standard curve was obtained by plotting the concentration against absorbance.

\section{ABTS radical scavenging activity}

ABTS $^{*+}$ was dissolved in methanol to a finial concentration of $7 \mathrm{mM}$. This radical cation was produced by reacting the ABTS $^{\cdot+}$ stock solution with $2.45 \mathrm{mM}$ potassium persulfate (final concentration) and by leaving the mixture for 12-16 h until the reaction was complete and the absorbance was stable. The ABTS $^{\circ+}$ stock solution was diluted in ethanol to an absorbance of $0.7 \pm 0.02$ at $734 \mathrm{~nm}$. After adding $0.9 \mathrm{ml}$ of the diluted $\mathrm{ABTS}^{\circ+}$ solution to $0.1 \mathrm{ml}$ of the sample and mixing them, the absorbance was taken 3 min later (Choi et al., 2012). This scavenging activity (\%) was expressed as a percentage using the following formula: ABTS radical scavenging activity $(\%)=(1-$ absorbance of sample $/$ absorbance of control $) \times 100$.

\section{Ferric reducing/antioxidant power (FRAP) assay}

The ferric reducing/antioxidant power (FRAP) assay developed by Choi et al. (2012) was used. Briefly, $1.5 \mathrm{ml}$ of working FRAP reagent pre-warmed to $37^{\circ} \mathrm{C}[300 \mathrm{mM}$ acetate buffer $(\mathrm{pH}$ 3.6):10 mM TPTZ in $40 \mathrm{mM} \mathrm{HCl}: 20 \mathrm{mM} \mathrm{FeCl}_{3}=10: 1: 1$ $(\mathrm{v} / \mathrm{v} / \mathrm{v})]$ was mixed with $50 \mu \mathrm{l}$ of the test samples and standards. This mixture was vortexed, and the absorbance at $593 \mathrm{~nm}$ was read against a reagent blank at a pre-determined time after the sample-reagent mixing. The test was performed at $37^{\circ} \mathrm{C}$, and a 0-4 min reaction time window was used.

\section{Statistical analysis}

All values are means of determinations in three independent experiments. Differences in the means of each value were determined by one-way ANOVA followed by the Tukey's multiple range tests at $P<0.05$ using the Statistical Analysis System software, Version 9.0 (SAS Institute, USA).

\section{Results and Discussion}

\section{Change of viable cell numbers and $\beta$-glycosidase activities during cheonggukjang fermentation of black soybeans}

The viable cell numbers and $\beta$-glycosidase activities increased with fermentation (Table 1). As the results, the viable cell numbers of bacteria in cheonggukjang fermentation of black soybeans range from 5.01 and $4.81 \mathrm{log} \mathrm{CFU} / \mathrm{ml}$ to 11.19 and $11.27 \log \mathrm{CFU} / \mathrm{ml}$, while the levels of $\beta$-glycosidase activity increased from an initial $(0 \mathrm{~h}) 4.2$ and $4.0 \mathrm{unit} / \mathrm{g}$ to 22.8 and $22.7 \mathrm{unit} / \mathrm{g}$ after $48 \mathrm{~h}$, respectively. Several studies reported that the viable cell numbers of Bacillus spp. increased depending on $\beta$-glycosidase activities increased during cheonggukjang fermentation (Yang et al., 2006; Cho et al., 2009, 2011).

\section{Change of total phenolic and isoflavone contents during cheonggukjang fermentation of black soybeans}

The change in the TPCs during cheonggukjang fermentation of two black soybeans (Seoritae and Seomoktae) is shown in 
Table 2. Distributions of 12 isoflavone contents during cheonggukjang fermentation of black soybeans by B. subtilis CSY 191

\begin{tabular}{|c|c|c|c|c|c|c|c|c|c|c|c|c|c|c|}
\hline \multirow{3}{*}{$\begin{array}{l}\text { Soybean } \\
\text { Cultivars }\end{array}$} & \multirow{3}{*}{ Samples } & \multicolumn{13}{|c|}{ Isoflavone contents $^{1)}(\mu \mathrm{g} / \mathrm{g})$} \\
\hline & & \multicolumn{3}{|c|}{ Glycosides } & \multicolumn{3}{|c|}{ Malonylglycosides } & \multicolumn{3}{|c|}{ Acetylglycosides } & \multicolumn{3}{|c|}{ Aglycones } & \\
\hline & & Daidzin & Glycitin & Genistin & Daidzin & Glycitin & Genistin & Daidzin & ilyciti & Genistin & Daidzein & Glycitein & Genistein & \\
\hline \multirow{2}{*}{ Seoritae } & UFBS $^{2)}$ & $603.2 \pm 30.11^{\mathrm{a}}$ & $217.5 \pm 10.18^{\mathrm{a}}$ & $913.1 \pm 45.65^{\mathrm{a}}$ & $160.5 \pm 8.00^{\mathrm{a}}$ & $22.7 \pm 1.01^{\mathrm{c}}$ & $274.9 \pm 13.74^{\mathrm{b}}$ & $\mathrm{nd}^{4)}$ & nd & $\operatorname{tr}$ & $111.1 \pm 5.65^{\mathrm{c}}$ & $101.7 \pm 51.21^{\mathrm{a}}$ & $63.5 \pm 3.22^{\mathrm{ab}}$ & 2463.3 \\
\hline & $\mathrm{FBS}^{3)}$ & $303.7 \pm 14.22^{\mathrm{c}}$ & $368.0 \pm 18.32^{\mathrm{a}}$ & $516.5 \pm 25.32^{\mathrm{c}}$ & $166.7 \pm 7.56^{\mathrm{a}}$ & $90.5 \pm 4.65^{\mathrm{a}}$ & $254.4 \pm 10.16^{\mathrm{bc}}$ & nd & $\operatorname{tr}^{5)}$ & $\operatorname{tr}$ & $253.0 \pm 12.66^{\mathrm{a}}$ & $72.5 \pm 3.06^{b}$ & $114.1 \pm 5.67^{\mathrm{a}}$ & 2139.2 \\
\hline \multirow{2}{*}{ eomoktae } & UFBS & $470.3 \pm 23.65^{\mathrm{b}}$ & $306.3 \pm 15.63^{\mathrm{ab}}$ & $747.9 \pm 37.20^{b}$ & $125.6 \pm 6.93^{\mathrm{b}}$ & $26.2 \pm 1.53^{\mathrm{c}}$ & $229.9 \pm 11.49^{c}$ & nd & $\operatorname{tr}$ & $\operatorname{tr}$ & $93.0 \pm 4.26^{\mathrm{d}}$ & $82.5 \pm 4.31^{b}$ & $42.4 \pm 2.31^{b}$ & 2124.2 \\
\hline & FBS & $279.0 \pm 13.81^{\mathrm{c}}$ & $353.5 \pm 16.26^{\mathrm{a}}$ & $489.8 \pm 24.34^{\mathrm{c}}$ & $179.2 \pm 8.99^{\mathrm{a}}$ & $56.6 \pm 2.38^{\mathrm{b}}$ & $330.7 \pm 13.23^{\mathrm{a}}$ & nd & nd & $\operatorname{tr}$ & $155.0 \pm 7.47^{b}$ & $46.4 \pm 2.33^{c}$ & $57.9 \pm 2.49^{\mathrm{ab}}$ & 1948. \\
\hline
\end{tabular}

${ }^{1)}$ Values indicate the mean's of three replications $(n=3)$. All values are means of determinations in three independent experiments. Means with different lowercase letters (a, b, and c) indicate significant differences of fermentation times by Tukey's multiple range test $(P<0.05)$.

2) UFBS, Unfermented black soybeans.

3) FBS, Fermented black soybeans at $37^{\circ} \mathrm{C}$ for $48 \mathrm{~h}$.

4) nd, not detected.

${ }^{5)} \mathrm{tr}$, trace $<0.002 \mu \mathrm{g} / \mathrm{g}$.

Fig. 1. The cheonggukjang of Seoritae and Seomoktae at $37^{\circ} \mathrm{C}$ for 0 and $48 \mathrm{~h}$ showed 15.05 (Seoritae) and 13.33 (Seomoktae) mg GAE/g dry weight and 20.37 and $17.93 \mathrm{mg}$ GAE/g dry weight, respectively (Fig. 1). The phenolics are secondary plant metabolites that are present in all plants. Phenolics are usually found in conjugated forms through hydroxyl groups with sugars and glycosides in plant materials (Juan and Chou, 2010). Catalyzing the release of the total phenolic contents from the soybean substrate during fermentation may thus lead to an increase in the content of those compounds, as shown in Fig. 1. Similar previous studies reported that the total phenolic content increased during soybean fermentation in foods, such as cheonggukjang and natto (Shon et al., 2007; Cho et al., 2009, 2011; Juan and Chou, 2010).

In the case of cheonggukjang of Seoritae soybean, the isoflavone-malonylglycoside and -aglycone contents increased throughout fermentation to approximately 1.3 - and 1.8 -fold relative to their starting amounts at $48 \mathrm{~h}(23.9 \%$ and $20.6 \%$, respectively), but the isoflavone-glycoside contents decreased from 70.2 to $55.5 \%$ at the end of fermentation (48 h). In the cheonggukjang of Seomoktae soybean, the levels of isoflavone-

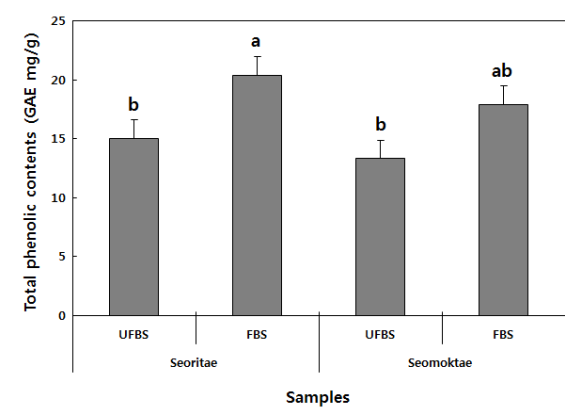

Fig. 1. Change of total phenolic contents during cheonggukjang fermentation of brown soybeans by B. subtilis CSY191. All values are means of determinations in three independent experiments. Means with different lowercase letters ( $a$ and $b$ ) indicate significant differences of fermentation times by Tukey's multiple range test $(P<0.05)$. malonylglycoside and -aglycone increased throughout fermentation to approximately 1.6 and 1.2 -fold relative to their starting amounts at $48 \mathrm{~h}(29.1 \%$ and $13.3 \%$, respectively), but the isoflavone-glycoside contents decreased to 71.2 to $57.6 \%$ at the end of the fermentation time (48 h) (Fig. 2). In particular, daidzin of the glycoside type decreased from $603.2 \mu \mathrm{g} / \mathrm{g}$ to $303.7 \mu \mathrm{g} / \mathrm{g}$, and the corresponding daidzein of the aglycone type increased to a maximum of $253.0 \mu \mathrm{g} / \mathrm{g}$ at $48 \mathrm{~h}$ during the fermentation process of Seoritae soybean (Table 2). The isoflavone-glycosides decreased, while the isoflavone-aglycones increased during cheonggukjang fermentation (Fig. 3A-3D).

The content and composition of these isoflavones vary in soybean foods depending on the soybean varieties and processing techniques used, such as fermentation. It has been reported that the isoflavone levels in soybean-containing foods, such as tofu, douchi, and cheonggukjang, decrease depending on the processing conditions (Coward et al., 1998; Jang et al., 2006; Prabhakaran et al., 2006; Yang et al., 2006; Cho et al., 2009, 2011). Jang et al. (2006) reported that the total isoflavone content in raw soybeans was $2.87 \mu \mathrm{g} / \mathrm{g}$, and this content decreased by approximately $50 \%$ during cooking prior to

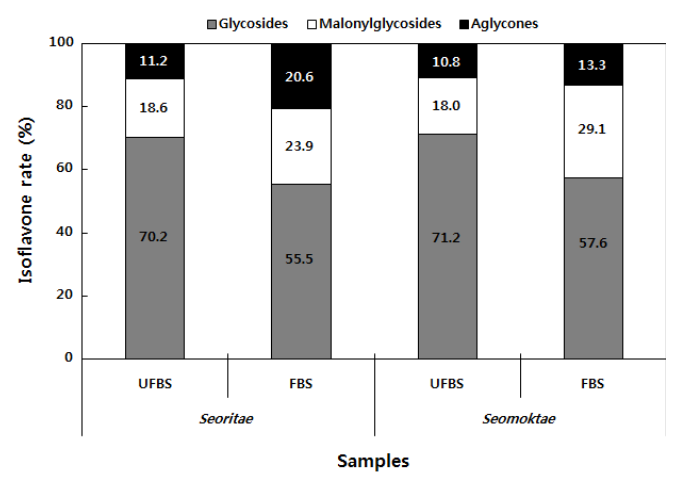

Fig. 2. Change of isoflavone- $\beta$-glycoside, -malonyl- $\beta$-glycoside, and -aglycones and total isoflavone contents during cheonggukjang fermentation of brown soybeans by $B$. subtilis CSY191. All values are means of determinations in three independent experiments. 

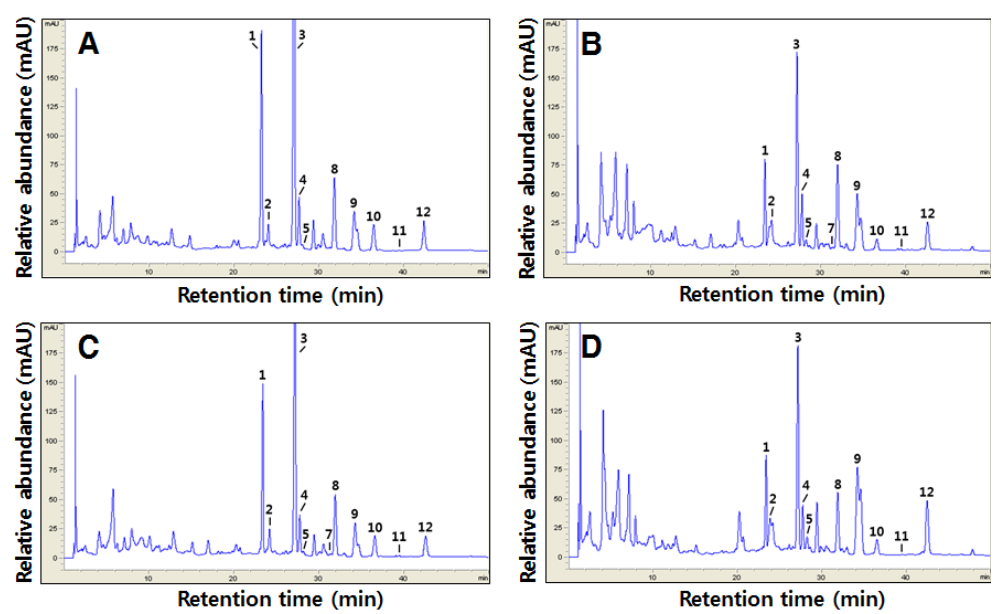

Fig. 3. Typical HPLC chromatograms of isoflavones. (A) HPLC chromatogram of isoflavone extract in cheonggukjang of Seoritae according to fermentation period ( $0 \mathrm{~h})$; (B) HPLC chromatogram of isoflavone extract in cheonggukjang of Seoritae according to fermentation period (48 h); (C) HPLC chromatogram of isoflavone extract in cheonggukjang of Seomoktae according to fermentation period (0 h); and (D) HPLC chromatogram of isoflavone extract in cheonggukjang of Seomoktae according to fermentation period (48 h). 1, daidzin; 2, glycitin; 3, genistin; 4, malonyldaidzin; 5, malonylglycitin; 7, acetylglycitin; 8, malonylgenistin; 9, daidzein; 10, glycitein; 11, acetylgenistein; and 12, genistein.

cheonggukjang fermentation. The total isoflavone content decreased from $1,055 \mu \mathrm{g} / \mathrm{g}(0 \mathrm{~h})$ to $870 \mu \mathrm{g} / \mathrm{g}(36 \mathrm{~h})$ during cheonggukjang fermentation by B. subtilis (Yang et al., 2006). Recently, Cho et al. (2011) showed that the total isoflavone content in cheonggukjang fermentation decreased approximately $64 \%$ from an initial $2923.21 \mu \mathrm{g} / \mathrm{g}$ to $1051.59 \mu \mathrm{g} / \mathrm{g}$ after $60 \mathrm{~h}$ of fermentation. In this study, the total isoflavone content decreased by approximately $13.2 \%$ and 9.0 after fermentation processing in raw soybeans from 2463.3 and $2124.2 \mu \mathrm{g} / \mathrm{g}$ to 2139.2 and $1948.1 \mu \mathrm{g} / \mathrm{g}$ at the end of fermentation (48 h), respectively (Table 2 ).

In general, most isoflavones in soybean are present in glycoside form, and they are converted into aglycones during fermentation by microbial $\beta$-glycosidase activity (Otieno et al., 2005; Yang et al., 2006; Wang et al., 2007; Cho et al., 2009, 2011). Cho et al. (2011) recently reported that the levels of isoflavone-aglycones increased, while the $\beta$-glycosidase activity and isoflavone-glycosides decreased during cheonggukjang fermentation by the potential probiotic B. subtilis CS90. In this study, we found that the starter potential probiotics $B$. subtilis CSY191 had the effect of increasing the $\beta$-glycosidase activity, and the aglycone contents increased over $48 \mathrm{~h}$. In contrast, Yang et al. (2006) reported that the addition of B. subtilis had no effect on $\beta$-glycosidase activity, and the aglycone contents did not increase during cheonggukjang fermentation.

\section{Change of antioxidant activities during cheonggukjang fermentation of black soybeans}

The cheonggukjang of Seoritae soybean exhibited stronger antioxidant activities than the cheonggukjang of Seomoktae soybean during fermentation periods of 0 and $48 \mathrm{~h}$ (Fig. 4).

To determine the hydrogen-donating antioxidants and chain-breaking antioxidants, we measured the ABTS radical
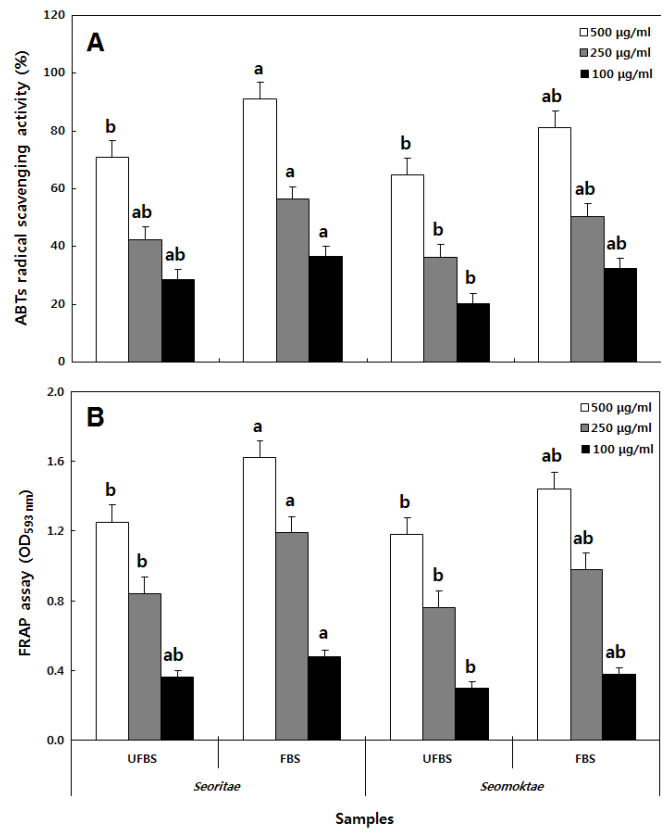

Fig. 4. Effects of antioxidant activity by cheonggukjang fermentation of black soybeans with B. subtilis CSY191. (A) Changes of ABTS radical scavenging activities during cheonggukjang fermentation; and (B) Changes of FRAP during cheonggukjang fermentation. All values are means of determinations in three independent experiments. All values are means of determinations in three independent experiments. Means with different lowercase letters (a and b) indicate significant differences of fermentation times by Tukey's multiple range test $(P<0.05)$. 
scavenging ability of cheonggukjang of Seoritae and Seomoktae soybeans. The levels of ABTS radical activity in cheonggukjang of Seoritae increased greatly from 70.81\% (500 $\mu \mathrm{g} / \mathrm{ml})$ at $0 \mathrm{~h}$ of fermentation to $91.06 \%$ at $48 \mathrm{~h}$ of fermentation. Additionally, the ABTS radical activities in cheonggukjang of Seormoktae increased greatly from $64.87 \%$ at $0 \mathrm{~h}$ of fermentation to $81.12 \%$ at $48 \mathrm{~h}$ of fermentation (Fig. 4A).

The FRAP assay is a direct test of the total antioxidant power. In the case of cheonggukjang of Seoritae, the values resulting from the FRAP assay of the fermented soybeans at $37^{\circ} \mathrm{C}$ for 0 and $48 \mathrm{~h}$ increased by $1.25(500 \mu \mathrm{g} / \mathrm{ml})$ and 1.62 , respectively. In the cheonggukjang of Seormoktae, the values resulting from FRAP assay of fermented soybeans at $37^{\circ} \mathrm{C}$ for 0 and $48 \mathrm{~h}$ increased by 1.18 and 1.44, respectively (Fig. 4B).

The total phenolic contents were measured as an overall indicator of the contents of these molecules with antioxidant properties (Slavin et al., 2009). Shon et al. (2007) reported that a methanol extract of cheonggukjang exhibited a radical-scavenging activity of $69-87 \%$ and total phenolic contents of $0.13-0.27 \mathrm{mg} / \mathrm{g}$. In particular, Juan and Chou (2010) found that fermentation enhanced the total phenolic content as well as antioxidant activity of the black soybean extract. Previously, many isoflavones were reported to have low scavenging potency for DPPH free radicals with scavenging effects only half that of $\alpha$-tocopherol and one-third that of epicatechin (Kao and Chen, 2006). However, isoflavones have direct free radical quenching ability, with daidzein and genistein being particularly effective (Shon et al., 2007; Cho et al., 2009, 2011). In addition, Kim et al. (2008) reported that the cheonggukjang extract and its constituents, genistein and daidzein, exhibited significant antioxidant activity in vitro. We recently reported that the radical scavenging activity increased from $53.6 \%$ to $93.9 \%$ depending on the total phenolic and isoflavone-aglycone (daidzein) contents during cheonggukjang fermentation by the potential probiotic B. subtilis CS90 (Cho et al., 2011). In particular, Kwak et al. (2007) suggested that the stronger antioxidant activity of cheonggukjnag might be related to the markedly higher total phenolic contents and isoflavone-aglycones and -malonylgycosides achieved during fermentation.

In conclusion, this study has documented for the first time that changes occur in the total phenolic contents and in the contents of 12 isoflavones during cheonggukjang fermentation of Korean black soybeans (Seoritae and Seomoktae) by the potential probiotic B. subtilis CSY191. Among these changes, the total phenolic and isoflavone-aglycone contents were markedly increased, while the isoflavone-glycosides were decreased according to the $\beta$-glycosidase activities. The total phenolic and total isoflavone contents and antioxidant activities were higher in cheonggukjang of Seoritae than cheonggukjang of Seomoktae at 0 and $48 \mathrm{~h}$ of fermentation. These results suggest that the high antioxidant activity of cheonggukjang fermentation of black soybeans might be related to the markedly higher total phenolic and isoflavone-aglycone contents achieved during fermentation.

\section{적 요}

잠재적인 생균제제 Bacillus subtilis CSY191에 의해 제조된 국산 검정콩(서리태 및 서목태) 청국장 발효 중 $\beta$-glycosidase 활 성, total phenolic와 isoflavone 함량 및 항산화 활성을 조사하였다. 청국장 발효 후 total phenolic 및 isoflavone-malonylgycoside와 -aglycone 함량은 증가하였고 이에 따라 ABTS 라디칼 소거활성 및 FRAP 활성은 증가하였으나 isoflavone-glycoside 함량은 감 소하였다. 특히, $37^{\circ} \mathrm{C}$ 에서 48 시간 발효된 서리태 청국장은 서목 태 원료 및 청국장보다 높은 활성을 나타내었다. 서리태 48 시간 발효 후, daidzein, glycitein 및 genistein의 함량은 각각 253.0 $\mu \mathrm{g} / \mathrm{g} 72.5 \mu \mathrm{g} / \mathrm{g}$ 및 $114.1 \mu \mathrm{g} / \mathrm{g}$ 을 나타내었다. 이 결과로부터, 검 정콩 청국장의 높은 항산화 활성은 total phenolic 및 isoflavonemalonylgycoside와 -aglycone 함량 증가에 의한 것으로 추측할 수 있다.

\section{Acknowledgements}

This research was supported by Gyeongnam National University of Science and Technology Grant (2012), Korea.

\section{References}

Cho, K.M., Hong, S.Y., Math, R.K., Lee, J.H., Kambiranda, D.M., Kim, J.M., Md. Islam, S.A., Yun, M.G., Cho, J.J., Lim, W.J., and et al. 2009. Biotransformation of phenolics (isoflavones, flavanols and phenolic acids) during the fermentation of cheonggukjang by Bacillus pumilus HY1. Food Chem. 114, 413-419.

Cho, K.M., Lee, J.H., Yun, H.D., Ahn, B.Y., Kim, H., and Seo, W.T. 2011. Changes of phytochemical constituents (isoflavones, flavanols, and phenolic acids) during cheonggukjang soybeans fermentation using potential probiotics Bacillus subtilis CS90. J. Food Comp. Anal. 24, 402-410

Choi, J.S., Kim, H.Y., Seo, W.T., Lee, J.H., and Cho, K.M. 2012. Roasting enhances antioxidant effect of bitter melon (Momordica charantia L.) increasing in flavan-3-ol and phenolic acid contents. Food Sci. Biotechnol. 21, 19-26.

Coward, L., Smith, M., Kirk, M., and Bames, S. 1998. Chemical modification of isoflavones in soyfoods during cooking and processing. American J. Clin. Nutr. 68, 1486-1491.

da Silva, L.H., Celeghini, R.M.S., and Chang, Y.K. 2011. Effect of the fermentation of whole soybean flour on the conversion of isolfavones from glycosides to aglycones. Food Chem. 128, 640 644.

Hu, Y., Ge, C., Yuan, W., Zhu, R., Zhang, W., Du, L., and Xue, J. 2010. Characterization of fermented black soybean natto inoculated with 
Bacillus natto during fermentation. J. Sci. Food Agric. 90, 1194 1202.

Jang, C.H., Lim, J.K., Kim, J.H., Park, C.S., Kwon, D.Y., Kim, Y.S., Shin, D.H., and Kim, J.S. 2006. Change of isoflavone content during manufacturing of cheonggukjang, a traditional Korean fermented soyfood. Food Sci. Biotechnol. 15, 643-646.

Jeong, T.L., Shih, Y.J., Wu, M.T., and Sung, J.M. 2010. Comparisons of flavonoids and anti-oxidative activities in seed coat, embryonic axis and cotyledon of black soybeans. Food Chem. 123, 1112-1116.

Juan, M.Y. and Chou, C.C. 2010. Enhancement of antioxidant activity, total phenolic and flavonoid content of black soybeans by solid state fermentation with Bacillus subtilis BCRC 14715. Food Microbiol. 27, 586-591.

Kao, T.H. and Chen, B.H. 2006. Functional components in soybean cake and their effects on antioxidant activity. J. Agric. Food Chem. 54, 7544-7555.

Kim, H.G., Kim, G.W., Oh, H., Yoo, S.Y., Kim, Y.O., and Oh, M.S. 2011. Influence of roasting on the antioxidant activity of small black soybean (Glycine max L. Merrill). LWT-Food Sci. Technol. 44, 992998.

Kim, N.Y., Song, E.J., Kwon, D.Y., Kim, H.P., and Heo, M.Y. 2008. Antioxidant and antigenotoxic activities of Korean fermented soybean. Food Chem. Toxicol. 46, 1184-1189.

Kwak, C.S., Lee, M.S., and Park, S.C. 2007. Higher antioxidant of chungkookjang, a fermented soybean paste, may be due to increased aglycone and malonylgycoside isoflavone during fermentation. Nutr. Res. 27, 719-727.

Lee, J.H. and Cho, K.M. 2012. Changes occurring in compositional components of black soybeans maintained at room temperature for different storage periods. Food Chem. 131, 161-169.

Lee, J.H. and Choung, M.G. 2011. Determination of optimal acid hydrolysis time of soybean isoflavones using drying oven and microwave assisted methods. Food Chem. 129, 577-582.

Lee, J.H., Nam, S.H., Seo, W.T., Yun, H.D., Hong, S.Y., Kim, M.K., and Cho, K.M. 2012. The production of surfactin during the fermentation of cheonggukjang by potential probiotic Bacillus subtilis CSY191 and the resultant growth suppression of MCF-7 human breast cancer cells. Food Chem. 131, 1347-1354.

Nam, Y.D., Yi, S.H., and Lim, S.I. 2012. Bacterial diversity of cheonggukjang, a traditional Korean fermented food, analyzed by barcoded pyrosequencing. Food Cont. 28, 135-142.

Otieno, D.O., Ashton, J.F., and Shah, N. 2005. Stability of $\beta$-glycosidase activity produced by Bifidobacterium and Lactobacillus spp. in fermented soymilk during processing and storage. J. Food Sci. 70, M236-M241.

Prabhakaran, M.P., Perera, C.O., and Valiyaveettil, S. 2006. Effect of different coagulants on the isoflavones levels and physical properties of prepared firm tofu. Food Chem. 99, 492-499.

Shon, M.Y., Lee, J., Choi, S.Y., Nam, S.H., Seo, K.I., Lee, S.W., Sung, N.J., and Park, S.K. 2007. Antioxidant and free radical scavenging activity of methanol extract of chungkukjang. J. Food Comp. Anal. 20, 113-118.

Slavin, M., Cheng, Z., Luther, M., Kenworthy, W., and Yu, L. 2009. Antioxidant properties and phenolic, isoflavone, tocopherol and carotenoid composition of Maryland-grown soybean lines with altered fatty acid profiles. Food Chem. 114, 20-27.

Wang, L., Yin, L., Li, D., Zou, L., Saito, M., Tatsumi, E., and Li, L. 2007. Influecnes of processing and $\mathrm{NaCl}$ supplementation on isoflavone contents and composition during douchi manufacturing. Food Chem. 101, 1247-1253.

Yang, S.O., Chang, P.S., and Lee, J.H. 2006. Isoflavone distribution and $\beta$-glycosidase activity in cheonggukjang, a traditional Korean whole soybean-fermented food. Food Sci. Biotechnol. 15, 96-101. 